\title{
Hepatosplenic T-cell lymphoma: Report of two cases
}

\author{
Ekarat Rattarittamrong ${ }^{1}$, Lalita Norrasethada ${ }^{1}$, Charin Ya-In ${ }^{2}$, Lertlakana Bhoopat ${ }^{2}$, Adisak \\ Tantiworawit ${ }^{1}$, Chatree Chai-Adisaksopa ${ }^{1}$, Weerasak Nawarawong ${ }^{1}$ \\ 1. Division of Hematology, Department of Internal Medicine, Faculty of Medicine, Chiang-Mai University, Chiang-Mai, \\ Thailand. 2. Department of Pathology, Faculty of Medicine, Chiang-Mai University, Chiang-Mai, Thailand.
}

Correspondence: Ekarat Rattarittamrong. Address: Division of Hematology, Department of Internal Medicine, Faculty of Medicine, Chiang-Mai University, Chiang-Mai, Thailand. Email: erattari@med.cmu.ac.th

Received: February 17, 2014

DOI : $10.5430 /$ crim.v1n2p54
Accepted: March 11, $2014 \quad$ Online Published: March 25, 2014

URL: http://dx.doi.org/10.5430/crim.v1n2p54

\section{Abstract}

Hepatosplenic T-cell lymphoma (HSTCL) is a rare type of lymphoma. Presenting with hepatosplenomegaly, fever, cytopenia without significant lymphadenopathy, most patients are young men with poor outcomes. Here is the report of two cases of HSTCL from Maharaj Nakorn Chiang-Mai Hospital, Thailand. Both patients were middle-aged men presented with prolonged fever, hepatosplenomegaly and cytopenia. Abnormal lymphoid cells, not demonstrated by flow cytometry, were microscopically revealed in the patients' bone marrow. The diagnosis of HSTCL was based on the histopathologic section obtained from splenectomy and liver biopsy. Both patients received cyclophosphamide, doxorubicin, vincristine, prednisolone (CHOP) regimen initially while one of them was salvaged with etoposide, methylprednisolone, cytarabine, cisplatin (ESHAP) and methotrexate, high-dose cytarabine, methylprednisolone (cycle B of hyperCVAD) regimen. They responded poorly to chemotherapy and succumbed to severe sepsis. The presented cases confirmed that HSTCL is very difficult to diagnose and current treatment modalities appear to be ineffective.

\section{Keywords}

Hepatosplenic T-cell lymphoma, T-cell lymphoma, Prolonged fever, Hepatosplenomegaly

\section{I ntroduction}

Hepatosplenic T-cell lymphoma (HSTCL) is a rare type of lymphoma, accounting for $1.4 \%$ of T-cell lymphomas (TCL) ${ }^{[1]}$. More than 200 cases were reported in literature but less than 20 cases in Asia ${ }^{[2]}$. In Thailand, only 3 HSTCL cases (less than 1\%) were reported from the cohort of 1983 lymphoma patients from Siriraj Hospital ${ }^{[3]}$ and none from the 939 lymphoma patients was reported by the Thai Lymphoma Study Group during 2007 and $2009^{[4]}$. HSTCL is usually composed of medium-sized lymphoid cells with marked sinusoidal infiltration of spleen, liver and bone marrow ${ }^{[5]}$. This subtype of lymphoma is more common in young men who are often presented with B-symptoms, hepatosplenomegaly, cytopenia without significant lymphadenopathy and have poor outcomes ${ }^{[6]}$. The authors report two additional cases of HSTCL from Maharaj Nakorn Chiang-Mai Hospital in Thailand. 


\section{Case presentation}

\subsection{Case 1}

A 27-year-old man presented with prolonged fever and significant weight loss for 4 months. Physical examination revealed hepatomegaly with liver palpable $5 \mathrm{~cm}$ below right costal margin and splenomegaly with spleen palpable $6 \mathrm{~cm}$ below left costal margin accompanied with multiple sub-centimeter axillary and inguinal lymph nodes. Further investigation showed severe neutropenia and mild thrombocytopenia (see Table 1) with hypoalbuminemia of $1.9 \mathrm{~g} / \mathrm{dl}$, elevated alkaline phosphatase and serum LDH of $355 \mathrm{U} / \mathrm{L}$ and $388 \mathrm{U} / \mathrm{L}$, respectively. Bone marrow (BM) examination revealed cellularity of 70\%-80\%, increased number of megakaryocytes and myeloid series, despite impaired myeloid maturation with scanty amount of mature neutrophils. Few abnormal medium sized lymphoid cells were observed. Unfortunately, the lymph node biopsy from both sides of inguinal region showed reactive hyperplasia. BM flow cytometry could not demonstrate abnormal lymphoid clone. The conventional cytogenetic study showed 46, XY. Computerized tomography (CT) scan of chest and abdomen showed multiple pulmonary nodules in both lungs, possibly lung involvement of lymphoma with bilateral pleural effusion, including hepatosplenomegaly and small abdominal lymphadenopathy.

Table 1. Serial complete blood count of case report 1

\begin{tabular}{|c|c|c|c|c|c|}
\hline Parameters & $\begin{array}{c}\text { 24/2/2009 } \\
\text { At } \\
\text { presentation }\end{array}$ & $\begin{array}{c}24 / 4 / 2009 \\
3 \text { days after } \\
\text { splenectomy }\end{array}$ & $\begin{array}{c}24 / 5 / 2009 \\
3 \text { weeks } \\
\text { after } 1^{\text {st }} \\
\text { CHOP }\end{array}$ & $\begin{array}{c}2 / 6 / 2009 \\
4 \text { weeks } \\
\text { after } 1^{\text {st }} \\
\text { CHOP }\end{array}$ & $\begin{array}{l}8 / 8 / 2009 \\
3 \text { weeks } \\
\text { after } 2^{\text {nd }} \\
\text { ESHAP }\end{array}$ \\
\hline Hemoglobin (g/dl) & 14.7 & 11.7 & 17 & 15 & 13.6 \\
\hline Hematocrit (\%) & 43.6 & 32.9 & 51 & 44 & 39.9 \\
\hline WBC (/cu.mm.) & 714 & 2700 & 8200 & 3300 & 4110 \\
\hline Neutrophils (\%) & 12 & 82 & 67 & 9 & 9 \\
\hline Lymphocytes (\%) & 81 & 16 & 19 & 87 & 77 \\
\hline Monocytes (\%) & 5 & 3 & 12 & 4 & 12 \\
\hline Eosinophils (\%) & 1 & 0 & 1 & 0 & 1 \\
\hline Basophils (\%) & 1 & 0 & 1 & 0 & 1 \\
\hline Platelet (/cu.mm.) & 67400 & 70240 & 100300 & 21000 & 208000 \\
\hline
\end{tabular}

Being suspicious of T-cell lymphoma with immune induced neutropenia and thrombocytopenia, the uneventful abdominal laparotomy was performed for splenectomy including liver biopsy. As a result, the significant improvement of systemic symptoms and cytopenia were observed within few days after the procedure (see Table 1).

\subsubsection{Pathology}

Spleen: The enlarged spleen weighed 775 grams with smooth capsule and firm consistency. Histopathology showed diffuse infiltration of neoplastic lymphoid cells in the red pulps with dilated sinusoids. These lymphoid cells expressed CD3+, CD4-, CD8- and CD56-. T-cell receptor (TCR) gene rearrangement revealed monoclonal pattern compatible with T-cell lymphoma.

Liver: The liver biopsy specimen was quite obvious with infiltration of neoplastic lymphocytes bearing indented vesicular nuclei along the sinusoids and the portal tracts. The neoplastic lymphocytes displayed similar immunohistochemistry reactivity as those in splenic tissue. These findings were consistent with infiltration of T-cell lymphoma within liver sinusoids. 


\subsubsection{Diagnosis}

Hepatosplenic T-cell lymphoma (HSTCL) stage IV. It should be noted that the definite diagnosis for this patient was obtained 6 months after his initial symptoms and 2 months after being presented to the hospital.

\subsubsection{Treatment}

This patient was initially treated with CHOP chemotherapy (cyclophosphamide, doxorubicin, vincristine, and prednisolone) and G-CSF support. Primary prophylactic antimicrobial against pneumocystis, herpes, and fungi was also given. He dramatically responded to chemotherapy with marked reduction in size of liver and normalization of blood counts (Table 1). However, on the $4^{\text {th }}$ week after induction, his liver became enlarged with palpable $4 \mathrm{~cm}$ below right costal margin, accompanied with recurrent neutropenia and thrombocytopenia. Flow cytometry examination of the BM revealed 60 percent of abnormal medium sized lymphoid cells, showing CD3+, CD5+, CD7+, CD8+, CD19-. As a consequence of early disease progression, the non-crossing over salvage chemotherapy with a combination of etoposide, methylprednisolone, cytarabine, and cisplatin (ESHAP regimen) was administrated with a transient clinical response.

After $2^{\text {nd }}$ cycles of ESHAP, he developed progressive hepatomegaly and recurrent neutropenia. The blood smear revealed leukoerythroblastic blood picture with circulating abnormal lymphoid cells (see Figure 1). BM examination showed hypercellularity with the presence of eighty percent abnormal lymphoid cells. Therapy was changed to methotrexate, high-dose cytarabine, methylprednisolone as a cycle B of hyper CVAD regimen. This was complicated with febrile neutropenia and invasive pulmonary aspergillosis. Despite broad spectrum antibiotics and antifungal treatment, pulmonary infection got worse as neutropenia had never recovered. The patient passed away within 6 months after the diagnosis of HSTCL.

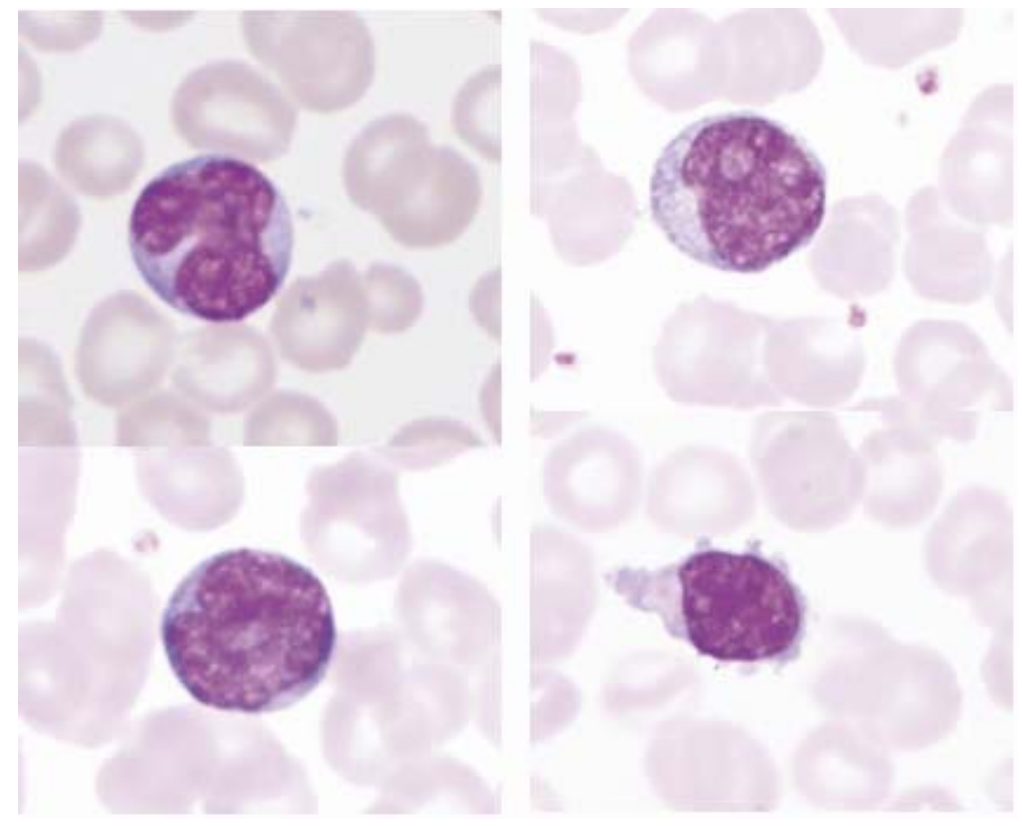

Figure 1. Circulating lymphoma cells of case report 1

\subsection{Case 2}

A 50-year-old man presented with prolonged fever, hepatosplenomegaly and pancytopenia for 1 month. Physical examination revealed mild pallor and jaundice with hepatomegaly with liver palpable $2 \mathrm{~cm}$ below right costal margin and splenomegaly with spleen palpable $8 \mathrm{~cm}$ below left costal margin, no lymphadenopathy. The patient was treated primarily at provincial hospital by transfusing 6 units of packed red cells. His CBC showed $\mathrm{Hb}$ of $10 \mathrm{~g} / \mathrm{dl}, \mathrm{Hct}$ of $30 \%$, WBC of 4030/cu.mm. (N52\%, L31\%) and platelet count of $34600 / \mathrm{cu} . \mathrm{mm}$. His serum albumin was low of $2.4 \mathrm{~g} / \mathrm{dl}$ with elevated alkaline phosphatase of $179 \mathrm{U} / \mathrm{L}$, accompanying with markedly elevated LDH of $2621 \mathrm{U} / \mathrm{L}$. BM examination revealed 
cellularity of $80 \%$, increased numbers of all erythroid, myeloid and megakaryocytic series. Twenty percent of BM nucleated cells were abnormal medium sized lymphoid cells with azurophilic granules (see Figure 2), though clonal lymphoid cells could not be detected by flow cytometry which being done without monoclonal antibody panel against TCR gamma-delta antigen. Significant dysplastic change was observed including megaloblastoid change, budding nucleus and irregular shape of nucleus of erythroid cells. CT scan of chest and abdomen showed marked hepatosplenomegaly with multiple area of splenic infarction. There were multiple subcentimeter lymph nodes in mediastinum, axilla and in porta hepatis with the largest node diameter of $2.0 \mathrm{~cm} \times 1.0 \mathrm{~cm}$. As being suspected of having lymphoma, splenectomy and liver biopsy was done to verify the diagnosis.

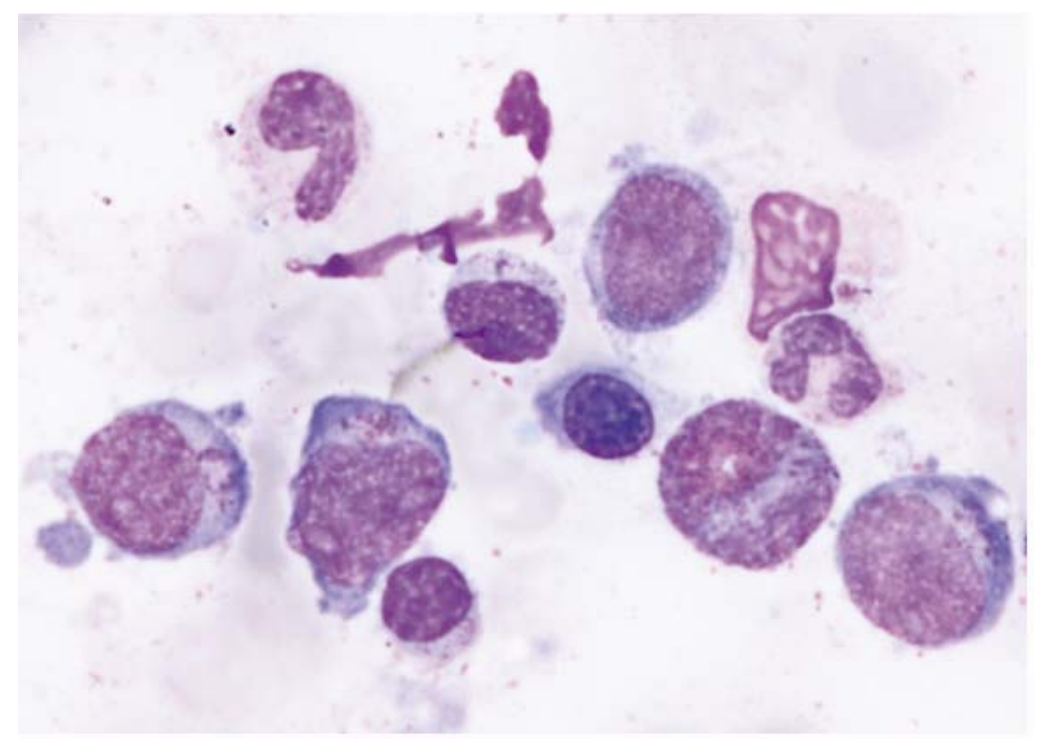

Figure 2. Abnormal lymphoid cells in the bone marrow of case report 2

\subsubsection{Pathology}

Spleen: The enlarged spleen weighed 2341 grams with smooth capsular surface. Histopathology showed marked reduction of the white pulps. The red pulps were diffusely infiltrated by medium-sized lymphoid cells in the cords and sinuses. Immunohistochemical staining revealed that the majority of lymphoid cells were positive for CD3 and CD45RO but negative for the other T-cell antigen, as well as CD20 and CD30. This finding was highly suspicious for the mature T-cell lymphoma.

Liver: The liver-biopsy specimen contained atypical medium-to-large lymphoid cells infiltrating in the vascular sinusoid. Immunohistochemical staining showed similar pattern as described for the spleen.

\subsubsection{Diagnosis}

Hepatosplenic T-cell lymphoma (HSTCL) stage IV. Of note, the diagnosis was achieved within 2 months after the initial symptoms and a month after being presented to the hospital.

\subsubsection{Treatment}

After splenectomy, his blood counts remained persistently low [platelet of $28000 / \mathrm{cu} . \mathrm{mm}$., Hb of $5.7 \mathrm{~g} / \mathrm{dl}$, and WBC of 7390/cu.mm. (N54\%, L28\%)]. According to his poor performance status and liver dysfunction, reduced dosage of CHOP chemotherapy with G-CSF support was administered. He continued to have intermittent fever with persistent thrombocytopenia with platelet count in the range of $20000-40000 / \mathrm{cu} . \mathrm{mm}$. Although, grade III-IV neutropenia never occurred, he developed progressive dyspnea and died from hospital-acquired pneumonia at 5 weeks after diagnosis of lymphoma. 


\section{Discussion}

These two cases demonstrated typical presentation of HSTCL including marked hepatosplenomegaly, thrombocytopenia, without significant lymphadenopathy or lymphocytosis ${ }^{[7]}$. From previous case series ${ }^{[2,8,9]}$, HSTCL typically occurs in young male at the median age of 30-40 years. Immunosuppression is the most important risk factor, especially post solid-organ transplantation. Splenomegaly is the most common presentation $(100 \%)$ and other common findings were hepatomegaly (77\%-88\%), B-symptoms (67\%-76\%), peripheral blood cytopenia including anemia (77\%-88\%), neutropenia (58\%-76\%), and thrombocytopenia (58\%-95\%) with scant lymphadenopathy $(0-11 \%)$. Blood chemistry usually shows abnormal liver function tests (38\%-100\%) and LDH elevation (55\%-69\%). In the majority of reported cases, the diagnosis of HSTCL was based on pathology from spleen and/or liver biopsy like this report. However, because of the characteristic and constant pattern of bone marrow involvement, bone marrow aspiration and biopsy are recommended as the first step for diagnosis ${ }^{[10]}$. BM aspiration specimens usually show hypercellular with trilineage hyperplasia accompanied with moderate infiltration of abnormal lymphoid cells. Although lymphoid infiltration is discrete, this may be subtle, and difficult to detect. This requires immunohistochemistry for demonstration of abnormal cells ${ }^{[1]}$. In case 1 , his neutropenia and thrombocytopenia can be explained by the process of immune induced cytopenia. This process was also observed in previous case reports of immune thrombocytopenia ${ }^{[8,12]}$ and autoimmune hemolytic anemia ${ }^{[13-15]}$. Myelodysplastic features as seen in BM from case 2 have been reported ${ }^{[16]}$ and they are possibly from inflammatory cytokines such as interleukin-6 (IL-6) and vascular endothelial growth factor (VEGF) or the patient may have previous myelodysplastic syndrome (MDS).

The neoplastic cells have the phenotype and genotype of immature cytotoxic T cells with CD3+, double negative for CD4 and $\mathrm{CD} 8$, aberrant loss of $\mathrm{CD} 5$ and $\mathrm{CD} 7{ }^{[17,18]}$. In spite of commonly positive NK cell markers (CD16+ and CD56+), these findings could not be found in these two patients. The availability of flow cytometry with monoclonal antibody against gamma-delta T-cell receptor (TCR) antigen in combination with a clinical suspicion and morphologic review of PBS would facilitate the diagnosis of HSTCL ${ }^{[10]}$.

HSTCL is a highly aggressive lymphoma showing a poor prognosis and resistance to conventional therapies ${ }^{[6]}$. From International Peripheral T-Cell and Natural Killer/T-Cell Lymphoma Study, 5-year failure-free and overall survival were $0 \%$ and $7 \%$, respectively which was the worst among all subtypes of T-cell lymphomas ${ }^{[1]}$. High-dose chemotherapy with autologous stem cell transplantation ${ }^{[9,19,20]}$ or allogeneic stem cell transplantation ${ }^{[20-23]}$ are potential treatment options to induce durable remission and should be recommended in HSTCL patients who are young and fit.

\section{Conclusion}

Although HSTCL is difficult to diagnose but the typical clinical presentation with careful examination of PBS and BM accompanied with proper investigation especially immunophenotyping can lead to the final diagnosis. Current treatment modalities with chemotherapy appear to be ineffective and further studies are needed to find the optimal therapeutic options for patients with HSTCL.

\section{References}

[1] International T-Cell Lymphoma Project. International Peripheral T-Cell and Natural Killer/T-Cell Lymphoma Study: Pathology findings and clinical outcomes. J Clin Oncol. 2008; 26: 4124-30. http://dx.doi.org/10.1200/JCO.2008.16.4558.

[2] Lu CL, Tang Y, Yang Q, Wang M, Zhao S, Bi C, et al. Hepatosplenic T-cell lymphoma: clinicopathologic, immunophenotypic, and molecular characterization of 17 Chinese cases. Hum Pathol. 2011; 42: 1965-78. http://dx.doi.org/10.1016/j.humpath.2011.01.034.

[3] Sukpanichnant S. Analysis of 1983 cases of malignant lymphoma in Thailand according to the World Health Organization Classification. Hum Path. 2004; 35: 224-30. http://dx.doi.org/10.1016/j.humpath.2003.10.007 
[4] Bunworasate U, Siritanaratanakul N, Khuhapinant A, Lekhakula A, Sirijerachai J, Chansung K, et al. A nationwide prospective multicenter study of clinical features and outcomes of non-Hodgkin lymphoma in Thailand: an analysis of 939 cases [abstract]. Blood. 2011; 118: 2064.

[5] Gaulard P, Jaffe ES, Krenacs L, Macon WR. Hepatosplenic T-cell lymphoma. In: Swerdlow S, Campo E, Harris NL, et al, eds. WHO Classification of tumours of haematopoietic and lymphoid tissues. Lyon, France: IARC; 2008: 292-293 p.

[6] Visnyei K, Grossbard ML, Shapira I. Hepatosplenic $\gamma \delta$ T-cell lymphoma: an overview. Clin Lymphoma Myeloma Leuk. 2013; 13: 360-9. http://dx.doi.org/10.1016/j.clml.2013.03.011

[7] Cooke CB, Krenacs L, Stetler-Stevenson M, Greiner TC, Raffeld M, Kingma DW, et al. Hepatosplenic T-cell lymphoma: a distinct clinicopathologic entity of cytotoxic gamma delta T-cell origin. Blood. 1996; 88: 4265-74.

[8] Weidmann E. Hepatosplenic T cell lymphoma: a review on 45 cases since the first report describing the disease as a distinct lymphoma entity in 1990. Leukemia. 2000; 14: 991-7. http://dx.doi.org/10.1038/sj.leu.2401784

[9] Belhadj K, Reyes F, Farcet JP, Tilly H, Bastard C, Angonin R, et al. Hepatosplenic gammadelta T-cell lymphoma is a rare clinicopathologic entity with poor outcome: report on a series of 21 patients. Blood. 2003; 102: 4261-9. http://dx.doi.org/10.1182/blood-2003-05-1675

[10] Iannitto E, Tripodo C. How I diagnose and treat splenic lymphomas. Blood. 2011; 117: 2585-95. http://dx.doi.org/10.1182/blood-2010-09-271437.

[11] Gaulard P, Belhadj K, Reyes F. Gamma-delta T-Cell lymphomas. Semin Hematol. 2003; 40: 233-243. http://dx.doi.org/10.1016/S0037-1963(03)00137-9

[12] Garderet L, Aoudjhane M, Bonte H, Lagrange M, Isnard F, Fouillard L, et al. Immune thrombocytopenic purpura: first symptom of gamma/delta T-cell lymphoma. Am J Pathol. 2001; 111: 242-3.

[13] Sallah S, Smith SV, Lony LC, Woodard P, Schmitz JL, Folds JD. Gamma/delta T-cell hepatosplenic lymphoma: review of the literature, diagnosis by flow cytometry and concomitant autoimmune hemolytic anemia. Ann Hematol. $2007 ; 74: 139$. http://dx.doi.org/10.1007/s002770050272

[14] Motta G, Vianello F, Menin C, De Nicolo A, Agata S, Altavilla G, et al. Hepatosplenic gammadelta T-cell lymphoma presenting with immune-mediated thrombocytopenia and hemolytic anemia (Evans' syndrome). Am J Hematol. 2002; 69: 272-6. http://dx.doi.org/10.1002/ajh.5555

[15] Minauchi K, Nishio M, Itoh T, Yamamoto S, Fujimoto K, Sato N, et al. Hepatosplenic alpha/beta T cell lymphoma presenting with cold agglutinin disease. Ann Hematol. 2007; 86: 155-7. http://dx.doi.org/10.1007/s00277-006-0212-3

[16] Takaku T, Miyazawa K, Sashida G, Shoji N, Shimamoto T, Yamaguchi N, et al. Hepatosplenic alphabeta T-cell lymphoma with myelodysplastic syndrome. Int J Hematol. 2005; 82: 143-7. http://dx.doi.org/10.1532/IJH97.04149

[17] Kehr E, Stenzel P, Xu G, Kelemen K. Leukemic phase of hepatosplenic T cell lymphoma: a case report and review of the literature. J Hematopathol. 2010; 3: 101-107. http://dx.doi.org/10.1007/s12308-010-0066-4

[18] Tripodo C, Iannitto E, Florena AM, Pucillo CE, Piccaluga PP, Franco V, et al. Gamma-delta T-cell lymphomas. Nat Rev Clin Oncol. 2009; 6: 707-17. http://dx.doi.org/10.1038/nrclinonc.2009.169

[19] Chen AI, McMillan A, Negrin RS, Horning SJ, Laport GG. Long-term results of autologous hematopoietic cell transplantation for peripheral T cell lymphoma: The Stanford experience. Biol Blood Marrow Transplant. 2008; 14: 741-7. http://dx.doi.org/10.1016/j.bbmt.2008.04.004.

[20] Voss MH, Lunning MA, Maragulia JC, Papadopoulos EB, Goldberg J, Zelenetz AD, Horwitz SM. Intensive induction chemotherapy followed by early high-dose therapy and hematopoietic stem cell transplantation results in improved outcome for patients with hepatosplenic T-cell lymphoma: a single institution experience. Clin Lymphoma, Myeloma Leuk. 2013; 13 : 8-14. http://dx.doi.org/10.1016/j.clml.2012.09.002.

[21] Konuma T, Ooi J, Takahashi S, Tomonari A, Tsukada N, Kobayashi A, et al. Allogeneic stem cell transplantation for hepatosplenic gammadelta T-cell lymphoma. Leuk Lymphoma. 2007; 48: 630-2. http://dx.doi.org/10.1080/10428190601126941

[22] Mansour MR, Dogan A, Morris EC, Khwaja A, Linch DC, Mackinnon S, et al. Allogeneic transplantation for hepatosplenic alphabeta T-cell lymphoma. Bone Marrow Transplant. 2005; 35: 931-4. http://dx.doi.org/10.1038/sj.bmt.1704897

[23] Machino T, Okoshi Y, Kaneko S, Obara N, Mukai HY, Suzukawa K, et al. Hepatosplenic alphabeta T-cell lymphoma successfully treated with allogeneic bone marrow transplantation. Bone Marrow Transplant. 2007; 39: 513-4. http://dx.doi.org/10.1038/sj.bmt.1705615 